\title{
Concordância de pronomes pessoais em frases copulativas
}

\author{
Maria Denilda Moura \\ Universidade Federal de Alagoas
}

Resumo: Na discussāo sobre a concordanncia de gênero, número e pessoa com pronomes em frases copulativas, procuramos mostrar a assimetria existente entre os traços de pronomes de 1 e $2^{a}$ pessoas vs. os pronomes de terceira pessoa, deteclada em construçōes copulativas. ern que o adjetivo/participio assume importante papel na concordância, em especial com os pronomes de $1^{i \prime}$ e $2^{\bar{a}}$ pessoas. Alguns dados diacrônicos sāo apresentados como evidèncias dos fenómenos ativos na lingua. Na busca de uाra explicaçāo satisfatória para os dados do PB, a hipótese DP (ABNEY 1987) e a hipótese da estrutura interna do DP pronominal (RITTER 1991. 1993, 1995) são discutidas.

Palavras-chave: Pronomes pessoais;

concordância; frases copulativas 


\section{Introdução}

A recorrência com que teóricos devárias tendências têm discutido a questão da concordância constitui forte indício para reconhecermos que a concordância ocupa lugar privilegiado na grande maioria das linguas estudadas. Estudos sobre a grande variedade de linguas: românicas, germânicas, semíticas, e várias outras têm permitido verificar semelhanças e diferenças não apenas entre as propriedades de línguas de uma mesma família, mas também entre as propriedades de línguas provenientes de origens diversas. E essa constatação, naturalmente, nos leva a refletir sobre o que é a concordầncia. Procuraremos a seguir apresentar uma breve discussão sobre a concordância, e sobre os principais tipos de concordância que têm sido investigados.

Corbett (2003a, P. 109) apresenta uma definição para agreement (concordância) retomando Steele (1978, p. 610): " o termo agreement geralmente se refere a uma co-variação sistemática entre uma propriedade semântica ou formal de um elemento e uma propriedade formal de outro". Mas, segundo Corbett, em Inglês, paralelamente a agreement, há concord, o que tem gerado muita confusão, não apenas por serem utilizados por alguns como sinônimos, mas também pela utilizaçāo feita por alguns linguistas, seguindo Bloomfield (1933, p. 191), que trata agreement como um termo supercomum, e distingue três tipos gerais de agreement, dentre os quais o primeiro é concord, que é por ele definido como 'agreement de modificadores dentro do grupo nominal e o agreement de predicados verbais'. Os outros tipos são: 'government' (regência), como em I know comparado a watch me; e 'cross-reference' (referéncia cruzada), como no Francês Jean où est-il?, literalmente 'Jean onde está ele?'. Além de destacar questões sobre a própria definição de concordância', Corbett retoma a questão da concordância como um fenômeno (ou um conjunto de fenômenos), e destaca outras questōes envolvidas na análise da concordância, tais como a dimensão do domínio
'Estamos utilizando o termo concordância para agreement ou concord, nos sentidos acima referidos, por ser o termo geralmente utilizado em portuguès para os fenômenos identificados. Agradecemos a Claudia Roberta Tavares Silva a leicura cuidadosa e as sugestões, em. uma primeira versảo deste texto, e destacamos que algumas sugestöes deverāo ser motivo de investigaçāo posteriormente. 
da concordância, se local ou nāo, e, ainda, a utilizaçào de noçōes como 'alvo' e 'controlador', se esses termos sāo apropriados ou não, e, em particular", se se crata de simetria ou de assimetria em concordância.

Nesse breve levantamento de questōes que envolvem a concordância, além da própria definiçāo, podemos perceber nitidamente que outros elementos entram em jogo para a sua análise. Apresentamos a seguir a posição de Anderson (2004), que questiona elementos relacionados ao fenômeno da concordância, além da própria definição, o que o leva a sugerir a reconstrução do termo. A discussão empreendida por Anderson (2004) parte de uma noção tradicional apoiada em um exemplo de concordância quando "a categoria formal de uma palavra depende de uma outra". Alguns exemplos de marcaçāo de caso em 'Georgian sentences' permitem constatar a imprecisào dessa definição. Por outro lado. Anderson considera o progresso da definiçāo de Ferguson "urn elemento gramatical $X$ se combina com um elemento gramatical $Y$ em função de alguma propriedade $Z$ de uma configuração gramatical". Anderson questiona essa definiçãoa partirdolevantamentodequestõessobrelínguas da familia Bantu que manifestam sistemas gramaticais de gênero. E, nesse caso, o problema levantado tem a ver com relaçōes estabelecidas entre um pronome que geralmente tem o mesmo gênero do DP com o qual ele estabelece uma relaçào anafórica, à exceção de casos em que o referente é humano, e um pronome de $1^{\text {a }}$ ou $2^{\circ}$ pessoas (geralmente. mas não sempre, usados para humanos) que é sempre usado, apesar do gênero do referente. A primeira vista. referência pronominal envolve identidade de traços, mas nesse caso outros elementos entram em jogo. Dessa forma, ele sugere que a questão da preferência dada ao pronome não seja considerada um exemplo de concordância, ao menos no sentido gramatical que tem sido utilizado, pelo fato de que ela não compartilha do outras propriedades de concordância: por exemplo, ela funciona arbitrariamente sobre extensōes do discurso. Além disso, ela depende 
claramente de fatores não gramaticais, tais como as opiniões do falante sobre os sentimentos por animais de estimaçāo, o conhecimento de características secundárias sobre o sexo, a existência de Nomes em outras línguas que pertencem a classes de gêneros arbitrários etc. E, nesse sentido, objetivando a coerência do objeto de estudo, tais relações de base semântica seriam distintas da noção gramatical de 'concordância', e ele faz referência à análise de Farkas e Zec (1995) sobre o romeno, em que os autores utilizam a teoria de Kamp 'Estrutura da Representação Discursiva', tendo em vista a necessidade de uma teoria diferente da teoria da concordância gramatical, para explicar fenômenos dessa natureza. ${ }^{2}$

Após as questōes acima levantadas, Anderson sugere que haja uma reconstruçào teórica, a fim de se obter uma melhor definição de concordância. Para ele, a teoria deveria eliminar o que não é próprio, "independente da teoria', à definição, a fim de reconstruir plenamente a noção intuitiva, segundo a qual 'concordância' é o que resulta da operação de uma regra de concordância. E para apoiar essa ideia, ele apresenta alguns pontos que precisam ser resolvidos segundo uma teoria plena da concordância: a) Domínio: qual a configuração em que a concordância se realiza?; b) Direcionalidade: a concordância vai de um elemento a outro, ou é justamente uma relaçāo? se for direcional, qual é a direcionalidade?; c) Localidade: quais os limites que existem para a relação entre elementos que concordam?; d) Traços: quais as propriedades de elementos gramaticais que concordam?; e) Rigor: sob que condiçōes a concordancia envolve menos do que identidade estrita nos traços envolvidos?; f) Conflito: o que acontece quando dois principios de concordância (sintático e semântico, tipicamente) são divergentes?; g) Referencialidade: qual a extensão do material da concordância que tem uma função referencial? como a concordancia referencial se relaciona com outros tipos de anáfora/ligaçāo?; h) Relação com clíticos: qual a relação entre clíticos pronominais e concordância?; i) Variação: o
2 Ver Menuzzi (2000) sobre relaçōes anafóricas no $\mathrm{PB}$. Com relaçāo à recorrència a uma estrunira de representaçāo discursiva, enfatizada por Anderson, queremos chestacar que procuraremos seguir uma perspectiva estritamente sintática; a nossa proposta, com base na análise de Ritter (1995), considera que o gênero está associado a categorias frásicas/ funcionais, e não a categorias funcionais associadas ao discurso. 
que acontece quando mais de um padrāo de concordância é gramatical, e a diferença corresponde a alguma outra coisa?; j) Função: em que sentido a concordância é boa?; l) Mudança: onde a concordancia se origina, e o que acontece a ela?; m) Realização: como a concordância é implementada formalmente?

Além desses pontos, ele destaca os dois tipos distintos de concordância que têm sido investigados: 1) a concordância entremodificadorese as cabeças desuas frases: 2) a concordância entre 'Predicados' e seus argumentos. Exemplificando esses dois tipos de concordância em várias línguas, e identificando os problemas que extrapolam as relações canônicas de concordância, Anderson finaliza seu texto com a afirmação a seguir, que sugere uma reconstruçāo teórica para se atingir uma melhor definiçāo para a concordância:

The importance of such examples for the studyof agreement lies in the fact that they show agreement to be a matter of cransfer of features. which may be realized in a varicty of ways in the morphology of the words on which they occur. This is opposed to a view on which agreement is a "morpheme" of the classical sort, a minimal and indissoluble association of form and meaning. If this were the right way to view agreement, we ought always to find exacrly one such marker corresponding to a single agreement relation. But of course, this is not an issue that affects ONLY' agreement ...

Nesse texto, além dessa breve apresentação sobre uma definição para a concordância e os principais tipos de concordância que têm sido considerados em várias análises, apresentaremos na seção 2, com base em dados do Porruguês Brasileiro, daqui em diante $\mathrm{PB}$, casos de concordância no PB. E na seção 3, esboçaremos algumas hipóteses de análise para os fenômenos detectados na 
seção 2, com base eñ duas hipóteses que têm apoiado estudos sobre a concordância em várias linguas: a hipótese DP (ABNEY 1987) e a hipótese da estrutura interna do DP-pronominal (RITTER 1991, 1993, 1995). Teceremos alguns comentários sobre algumas análises inspiradas nessas hipóteses, em especial Cardinaletti (1994, 1997, 1999, 2004), Cardinaletri \& Starke (1999), dentre outros.

\section{O fenômeno da concordância no $\mathrm{PB}^{3}$}

Queremos destacar inicialmente que estamos adotando a proposta de Anderson (2004), em termos de uma reconstrução teórica para se atingir uma definição de concordância mais coerente com os tipos de fenômenos que abrangem a questāo da concordância.

Estudos sobre uma grande variedade de línguas: românicas, germânicas, semiticas e várias outras têm permitido verificar semelhanças e diferenças nâo apenas entre línguas de uma mesma família, mas também entre propriedades de línguas provenientes de origens diversas. Esses estudos geralmente tracam de dois tipos de concordância: a) entre os modificadores e os núcleos de suas frases; b) e a concordância entre 'predicados' e seus argumentos, como visto acima. A concordância do tipo (b), argumento-predicado, não envolve apenas transmissão de traços (do argumento para o predicado), mas também uma relação referencial entre os traços de concordância e o argumento que os fornece.

Anderson (2004, p. 6) destaca dois tipos de concordância argumento-predicado. Muitas das variedades geralmente discutidas envolvem a concordância de verbos com seus argumentos (sujeitos e outros) em traços de pessoa e/ou número, às vezes também estendendo-se a gênero. $O$ outro tipo envolve concordância de predicados adjetivais, incluindo particípios, com um argumento em termos de gênero e número. A questão da localidade/domínio, que é pertinente para a concordância argumento-predicado, é derivada da conhecida convenção do "ciclo estrito",
Queremos destacar que estamos apreșentando apenas alguns casos sobre o fenôneno da concordância no PB. Abordaremos em especial casos sobre a questāo da concordância que aferam (pro)nomes e adjetivos/participios. Temos consciéncia de que o fenômeno da concordància abrange uma gama mujto mais ampla de fenômenos, nāo apenas emı $\mathrm{PB}$, mas também em várias outras línguas. 
+ Vale destacar que nenhum dos marcadores de palavras é exclusivamente associado a gênero, alguns marcam mesmo palavras sem género, tais como advérbjos e preposiçôes. Harris sugere que a relação entre raarcadores de classes de palavras e gênero é uma relação indireta.

5 Na subseçăo 2.3 , veremos alguns elementos da diacronia que ilustrain a origem de vărios fenômenos ainda ativos no PB. atualmente substituida pela noção de derivação por fas (CHOMSKY, 1999).

A partir de dados do PB, veremos a seguir algun; casos de concordância de nomes e, em seguida, algums casos envolvendo pronomes.

\subsection{A concordância do DP em frases copulativas}

Com relação aos nomes, e com base na análise de Harris (1991), Ritter (1993) agrupa sete diferentes padrōes. elencados por Harris, em três classes: pares de nomes que têm formas diferentes relacionadas ao masculino e ao feminino, nomes que podem ser masculinos ou femininos dependendo de seu referente, e "suppletive pairs" (formas lexicais distintas). Essas três classes podem ser ilustradss no PB em (1):
masculino
feminino
a . menino menina
b. filho
filha
c. estudante
d. jovem
e. rapaz
moça
f. homem
mulher

Em (a-b), as vogais sublinhadas pertencem a um conjunto de morfemas denominados por Harris de marcadores de palavras, que têm por função marcar um nome derivacional e flexionalmente. ${ }^{+}$Em (1c-d). temos nomes que podem ser masculinos ou femininos. dependendo do referente, e em (1e-f), temos os 'suppletive pairs'.5 Cumpre destacar que, no PB. o par o/a tradicionalmente identifica as marcas dos dois gêneros ativos na língua (masculino e feminino). tanto nos nomes quanto no marcador de definitud. em $D$ (determinante).

A partir dos dados vistos enn (1), podemos ter no PB sentenças como as ilustradas em (2)-(4): 
(2) a. O menino é bonito/leal

A menina é bonita / leal

b. Os meninos sāo bonitos / leais

As meninas são bonitas / leais

(3) a, O estudante é bonito/leal

A escrudante é bonita / leal

b. Os estudantes são bonitos / leais

As estudantes sảo bonitas / leais

(4) a. Esse rapaz é bonito / leal

Essa moça é bonita / leal

b. Esses rapazes são bonitos / leais

Essas moças são bonitas / leais

Nos exemplos acima, podemos observar não apenas a influência das três classes vistas acima, na estrutura interna do DP, em especial em termos das marcas visíveis de gênero, apenas em D (determinante), ou duplamente marcado no determinante e no nome. Mas podemos observar também uma assimetria referente aos adjetivos, em se tratando de frases copulativas, no que concerne à presença ou ausência de marca visivel de gênero na concordância do adjetivo. O fenómeno que foi observado na segunda classe dos pares de nomes apresentados em (1) ocorre igualmente com os adjetivos, e podemos afirmar, ainda, que mesmo em sentenças sem cópula, em que o adjetivo funciona como um modificar do nome no DP, encontramos igualmente o mesmo fenómeno, como pode ser visto nos exemplos de (5):

(5) a. O joveın elegante desfilou na passarela

A jovem elegante desfilou na passarela

b. Os jovens elegantes desfilaram na passarela As jovens elegantes desfilaram na passarela 


\subsection{A concordância do DP pronominal em frases copulativas}

Algumas análises sobre o DP pronominal têm apresentado evidências que comprovam a oposiçāo de pronomes de 1 a e $2^{a}$ pessoas vs, pronomes de $3^{a}$ pessoa (RITTER 1995), Déchaine \& Wiltschko (2002), Rulmann (2004), Wechsler (2003), Harley \& Ritter (2002), dentre outros.

No $\mathrm{PB}$, nós podemos distınguir nitidamente uma diferença entre os pronomes de $1^{\text {a }}$ e $2^{a}$ pessoas e os pronomes de $3^{3}$ pessoa, nem sempre pelas mesmas razöes apontadas nas análises acima referidas. Os exemplos de (6) permitem verificar o que ocorre no $\mathrm{PB}$ :

(6) a. eu estou interessado / feliz

eu estou interessada / feliz

b. você está interessado / feliz você está interessada / feliz

c. ele está interessado / feliz ela está interessada / feliz

d. nós estamos interessados / felizes nós estamos interessadas / felizes

e. a gente está interessado / feliz a gente está interessada / feliz

f. vocês estão interessados / felizes vocès estāo interessadas / felizes

g. eles estäo interessados / felizes elas estão interessadas / felizes

Nós destacamos os pronomes de 3 a pessoa, tanto no singular quanto no plural, para mostrar a assimetria entre esses pronomes e os de $1^{\text {a }}$ e $2^{a}$ pessoas, quanto ao traço de gênero, não visível nas últimas. Como podemos perceber nos exemplos de ( $6 a, b, d, e, f)$, uma única forma pronominal desencadeia dois padrões de concordância de gênero com a forma adjetival, quando esta contérn visivelmente o traço de gênero, enquanto os pronomes de 3 a pessoa comportam visivelmente os traços de gênero. 
e esses estão contidos, visivelmente, na forma adjetival, quando esta tem marcação de gênero, como vimos, também, nos exemplos (2)-(4) acima. Esses fatos nos permitem identificar a assimetria existente, quanto aos traços de gênero, entre os pronomes de $1^{\mathfrak{a}}$ e de $2^{\mathfrak{a}}$ pessoas vs. os pronomes de $3^{3}$ pessoa.

\subsection{Alguns dados da diacronia}

Os pronomes pessoais da $1^{\text {a }}$ e $2^{\text {a }}$ pessoas provêm de pronomes pessoais latinos, e os da 3 a pessoa, do pronome demonstrativo latino ille, que foi pouco a pouco empregado como pronome pessoal. A $1^{\text {? }}$ pessoa do singular vem do nominativo ego > eo > eu; a $2^{3}$ pessoa do singular vern do

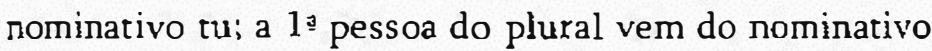
nos > nós; a $2^{2}$ pessoa do plural, do nominativo vos > vós; a $3^{2}$ pessoa do singular vem do demonstrativo latino ille > ele, illa > ela; a $3^{a}$ pessoa do plural eles, elas, é resultado das formas do singular ele e ela, com a desinência -s, característica do plural em português (cf. SOUSA DA SILVEIRA 1972, p. 117-119).

Para Said Ali, os pronomes pessoais usam-se todos como absolutos. Têm singular e plural e formas de nominativo, dativo e acusativo. Alguns (os da 3o pessoa) distinguem o gênero. Dividem-se em pronomes de $1^{1}$, $2^{3}$ e 3 s pessoa. Eu, pronome de 13 pessoa, representa o indivíduo que fala; o seu plural nós significa esta mesma pessoa associada a outra ou outras: eu + tu; eu + ele; eu + vós etc. Tu e vós são os pronomes de $2 \mathfrak{a}$ pessoa; ele, ela, eles, elas são os da $3^{a}$ pessoa. Do uso da forma vossa mercê nasceu a variante você. Servimo-nos também de vocês como plural semântico de cu. O pronome vós caiu em desuso, quer para denotar pluralidade de pessoas. quer como tratamento de polidez (1971, p. 93).

O surgimento tardio dos pronomes de 3 sessoa em oposição aos pronomes de $1^{\mathrm{a}}$ e $2 \mathrm{a}$ pessoas é destacado por Tarallo (1970). Para ele, a grande inovaçāo no latim falado e, posteriormente, nas línguas românicas, foi o uso de um pronome pessoal de terceira pessoa, gramaticalizando-o 
aos sistemas em evolução. No sistema do latim clássico, contudo, a pessoa do verbo era freqüentemente marcada apenas pela flexão verbal, sendo os pronomes de primeira e de segunda pessoas usados apenas enfaticamente (ou ainda redundantemente).

De acordo com a categoria de casos, em virtude da qual a forma prosominal, como a nominal, variava morfologicamente como nominativo, acusativo, genitivo etc., as formas ego e tu, que eram de nominativo, alternavam, respectivamente, com outras, que eram de genitivo (mei, tui), de dativo (mihi, tibi) e de acusativo-ablativo (me, te). No sistema morfológico geral da língua latina, eram essas outras formas as de uso constante e frequiente, porque a indicação do falante ou do ouvinte como sujeito, que cabia a ego ou tu, conforme o caso, vinha dada em desinência na própria forma verbal. Nestas condiçôes, ego e tu só se empregavamn pot uma redundância enfática ou como 'vocativos', numa comunicação isolada. ou numa frase de verbo inexpresso (Ego bônus. 'Eu sou bom'), cf. Williams (1975, p. 145) apud Tarallo (1970, p. 138).

Assim, contrariamente ao sistema do latim clássico, encontramos em português, ao lado de eu, tu, nós, vós, as formas ele, ela, eles, elas, oriundas do demonstrativo ille, desprovido, entretanto, de sua função dêitica. O timbre fechado em ele e aberto em ela é explicado de diferentes formas pela gramática histórica: ou a diferença de timbre espelha uma distinção morfológica de gêneto, masculino e feminino; ou a vogal se abriu em ela cm metafonia com a vogal final /a/. As formas de plural são criaçōes românicas (cf. TARALLO, op. cit. p. 138-9).

Como podemos observar nas referências acima, a distinção morfológíca de gênero apenas nos pronomes de $3^{3}$ pessoa tem motivação histórica, tendo em vista a 
sua origem, a partir dos pronomes demonstrativos latinos ille > ele / illa > ela, diferentemente das formas de $1^{\mathrm{x}} \mathrm{e}$ 2 pessoas que, no sistema morfológico do latim, vinham contidas na própria forma verbal.

Quanto aos artigos, o fato de terem se originado também do demonstrativo latino, mesmo tardiamente, perrnite constatarmos em todas as suas formas as marcas (ou traços) de número e gênero. Tarallo (op. cit., p. 137) destaca que "săo os autores unânimes quanto ao fato de o sistema do latim clássico não possuir artigo, e de essa classe de palavras ter surgido somente nos derradeiros momentos do latim falado, já em fase pré-romanço. Nāo há dúvida ou desacordo, tampouco, quanto ao fato de o artigo definido ter "nascido" de um pronome demonstrativo, mais especificamente, ille, em sua forma acusativa. Assim: masculino singular: illu > elo $>$ lo $>0$; feminino singular: illa $>$ ela $>$ la $>$ a; masculino plural: illos > elos > los > os; feminino plural: illas > elas > las > as. ${ }^{6}$

Sobre a questão da concordancia, alguns dos fenómenos identificados nas duas subseçōes anteriores encontram na história da língua algumas evidências qué corroboram as assimetrias detectadas. Said Ali (op. cit., p. 279) destaca alguns pontos: "a concordância não é, como parecerá à primeira vista, uma necessidade imperiosamente ditada pela lógica. Repetir num termo determinante ou informativo o gênero, número ou pessoa já marcados no termo determinado ou de que se fala, é antes uma redundância. Daqui vem o desaparecimento da flexāo (e portanto da concordância) do adjetivo predicativo em alemão e do adjetivo, quer predicativo quer atributivo em inglês. $O$ sistema de sufixos de pessoa, tāo desenvolvido no verbo das antigas línguas sintéticas, e que caracterizava a concordância do verbo com o sujeito, perdeu o seu valor em muitas línguas modernas, bastando nestas mencionar-se o pronome sujeito. No imperfeito do verbo inglês perdura a concordância para a $2^{2}$ pessoa do singular. Para as demais pessoas do mesmo tempo, a regra que manda concordar o verbo com o sujeito é mera
- Os pronomes cliticos (o, a, os, as) têm reconstrução idểntica à dos artigos, ef. Tarallo (1990, p. 137). 
7 Essa questảo e o caso dos determinantes constituidos de numerajs serāo discutidos em urn outro momento. ficçāo; diz-se loved, indiferentemente para I, he, we, you e they. Em nosso idioma, posto que digamos um, uma, dous, duas, duzentos, duzentas ctc., ninguém repara na falta de análoga variação de gênero para os quantitativos três, quatro, cinco etc. Os qualitativos em -e não são menos adjetivos que os que acabam em -0 ; mas a regra de concordância só os atinge quanto ao número, singular ou plural, e năo acode a ninguém a lembrança de que se deveria distinguir formalmente homem pobre e mulher pobre do mesmo modo que se diferença homem rico e mulher rica" (sic).

Como podemos constatar na afirmação de Said Ali, além da variação interlinguística, há assimetria verificada tanto па relação argumento/predicado, envolvendo a concordância do verbo com o seu argumento, em termos dos traços de pessoa e número (caso do inglês), como na concordância de um predicado adjetival com um argumento em termos dos traços de gênero e número (caso do inglês e do alemāo). Quanto ao português, temos o que poderíamos considerar um "caso misto"; dependendo das propriedades morfológicas do adjetivo, há uma variação quanto à visibilidade dos traços de gênero no argumento e no predicado. Como vimos nos exemplos de (2)-(5), esse mesmo tipo de fenômeno é verificado com relação aos argumentos nominais, e, nesse caso, a classificaçāo vista em (1) permite agrupar os três tipos identificados. A exemplo do que foi construído com relaçāo aos nomes. acreditamos ser possível, também, pensarmos em uma classificação semelhante com relaçâo aos adjetivos. ${ }^{\text {? }}$

A origem dos traços de número e gênero nos nomes e adjetivos é destacada por Chaves de Melo (1957): "na morfologia, no sistema flexional, mostra-se ainda a língua portuguesa muito conservadora e muito rica. Apresenta plural sigmático, e isso tem causa histórica: os substantivos e adjetivos da língua continuam, na sua quase totalidade, o acusativo latino, que é o caso que sobreviveu na Península Ibérica. Ora, como todo acusativo plural latino tem $-s$, com $-s$ se faz o plural vernáculo. A flexầ 
feminina é a, porque a maior parte das palavras femininas procedern da primeira declinação latina, cujo acusativo era em am (a, no latim vulgar tardio). Por isso, definida a fisionomia morfológica da língua, esse a do acusativo passou a valer como desinência ou sinal de feminino, o que, aliás, já acontecia em latim vulgar, como se vê, entre tantos exemplos, das correções 169 e 170 do Appendix Probi: "nurus non nura" e "socrus non socra". Daí vem que algumas palavras procedentes da terceira declinação, outrora desprovidas de formas especiais para o feminino, receberam uma flexāo de gênero analógica, por acréscimo de -a . Na língua arcaica não tinham formas especiais para o feminino os nomes em -or, em -ol, em -ês e em -nte: dizia-se o pastor, a pastor, o espanhol, a espanhol, o português, a português, o infante, a infante. Ainda temos vestigios disso em nomes como cortês, pedrês, montês, incolor, multicor etc., invariáveis no feminino" (cf. $P$. 185).

Como podemos constatar nas várias posições assumidas pelos autores acima referidos, muitos dos fenômenos ativos na língua atualmente encontram motivação histórica para a sua realização. Para finalizar esta seção, teceremos algumas considerações sobre o gênero, com base em Corbett (1999) [1991], em especial, e algumas consideraçōes sobre a questão do adjetivo predicativo, em particular.

\subsection{A questão do gênero}

Para Corbett, a palavra gênero é usada não apenas para um conjunto de nomes, mas também para uma categoria. Assim, podemos dizer que uma língua particular tem três gêneros, masculino feminino e neutro, e que a língua tem a caregoria gênero."

Sobre a determinação dos critérios de identificaçâo do gênero, o autor destaca que urna das formas de fazêlo é através da concordância, sendo esta a forma como os gêneros são 'refletidos no comportamento de palavras associadas', no sentido de Hockett. Dizer, por exemplo, 
que uma língua tem três gêneros significa que existem três classes de nomes que podem ser distintos sintaticamente pelas concordâncias que recebem. E destaca, ainda, que essa é a perspectiva geralmente aceita para o gênero.

Como uma consequência de rer a concordância como critério é que a definição de concordância por el mesma torna-se muito importante, e cita como exemplo o caso dos pronomes. Muitos estudiosos que trabalham sobre a concordancia incluem o controle de pronomes anafóricos por seu antecedente (the girl ... she) como parte da concordancia. Se isso for aceito, então as línguas em que pronomes sejam apresentados como a única evidêncìa para gênero seriam reconhecidas como tendo um sistema de gênero. Assumindo essa posição, ele assinala que tạ posiçāo nāo é aceita universalmente, e vai chamar tais sistemas de 'sistemas pronominais de gênero', já que isso levanta alguns problemas, por exemplo, possiveis divergências em concordância de gênero.

Sobre o 'alvo do gênero', a complexidade existente nas línguas merece atenção. Corbett assinala que nāo são apenas os adjetivos e os verbos que poden exibir concordância em gênero, mas em algumas línguas advérbios concordam, cm outras, numerais, e, algumas vezes, mesmo conjunções concordam em gênero, o que o leva a destacar a importância de se descrever os sistemas complexos de gênero que ocorrem surpreendentemente nas línguas.

Tendo em vista os dados do PB apresentados em (2.1) e (2.2), iremos direcionar nossa reflexão sobre a concordancia argumento/predicado, em especial envolvendo (pro)nomes e adjetivos/particípios. É o que discutiremos na seção seguinte.

\section{Hipóteses (e problemas) para uma proposta de análise}

O nosso ponto de partida para uma discussão sobre a questão da concordância do DP pronominal no PB levará em consideração duas hipóteses que têm 
apoiado muitas análises sobre a concordância em várias linguas: a hipótese DP (ABNEY 1987) e a hipótese da estrutura interna do DP pronominal (RITTER, 1991, 1993, 1995). Tendo em vista as várias análises inspiradas nessas hipóteses: Cardinaletti (1994, 1997, 1999, 2004), Cardinaletti \& Starke (1999), Danon (1996), Carstens (2000), Déchaine e Wilsschko (2002), Rullmann (2004), en especial sobre o PB, Galves (2001), Magalhäes (2004), dentre outros, teceremos algumas consideraçōes sobre aspectos dessas análises quando se fizer necessário.

Quanto à hipótese do DP, de Abney (1987), é afirmado que o determinante é a cabeça da categoria funcional (D) que seleciona o NP como complemento. Em sua análise, ele trata especialmente dos artigos em línguas como o inglês, não considerando outros tipos de determinantes ou a formulaçâo de outras categorias funcionais nominais. Essa questão será retomada posteriormente.

Abney (1987) assume a posição original de Postal (1966) de que os pronornes pertencem à mesma categoria sintática dos determinantes, e propõe sua análise de pronomes como DPs que têm apenas uma cabeça funcional D. Ritter (1995), em seu estudo sobre a categoria sintática de pronomes e a concordância em hebraico moderno, propõe a hipótese de duas categorias funcionais nominais que permita uma explicação estrutural para a diferença na distribuição de elementos que funcionam como pronomes

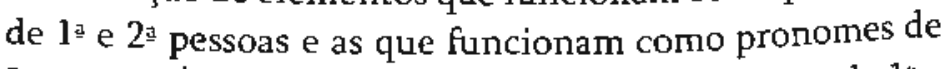
$3^{\mathrm{a}}$ pessoa. É levantada a hipótese de que pronomes de 1 i e de 2 a pessoas são DPs que contêm apenas a cabeça $D$ e que essa cabeça é especificada para pessoa, número e gênero, enquanto pronomes de 3 a pessoa tâm uma estrucura mais complexa, em que D é especificado para pessoa e Num é especificado para número e gênero". Com a associação de pronomes à concordância, é afirmado que a diferença entre pronomes e concordância não se encontra em sua categoria, mas em seu papel na sintaxe. Para Ritter, as categorias funcionais encontradas em frases nominais
9 Ritter (1995) destaca que en hebraico há semelhanças entre a concordância no tempo passado es pronomes de $1^{\mathrm{a}}$ e $2^{\mathrm{a}}$ pessoas, de um lado, e entre a concordància no tempo presente e pronones de 3 pessoa, de outro lado, o que sugere que as mesmas categorias nominais que servem de pronome também servem de coucordância. Ou seja, diferentemente do portugués, os traços de gênero em hebraico estão presentes também no verbo, segundo as especificaçôes apontadas com relação ao tempo preserte e ao tempo passado. E, como vimos en (2.3) acirna, fato correlato ocorreu no latim clássico, cf. Tatallo (1970). 
plenas são atestadas também no sistema pronominal do hebraico, e salienta que sua hipótese de duas categorias funcionais distintas permite identificar duas classes estruturalmente distintas de pronomes nessa língua.

Por outro lado, a análise das construçōes genitivas de Ritter (1991) fornece motivação in dependente para uma projeção intermediária entre D e $\mathrm{N}$, a projeçāo NurnP. A discussão de gênero e número em frases nominais plenas estabelece que em hebraico a especificação de gênero está ná cabeça do NP; a especificação de número está em NumP; e 'definiteness' está na cabeça do DP. Assim, as formas nominais plenas têrm a representação (7) a seguir, (16) em Ritter;

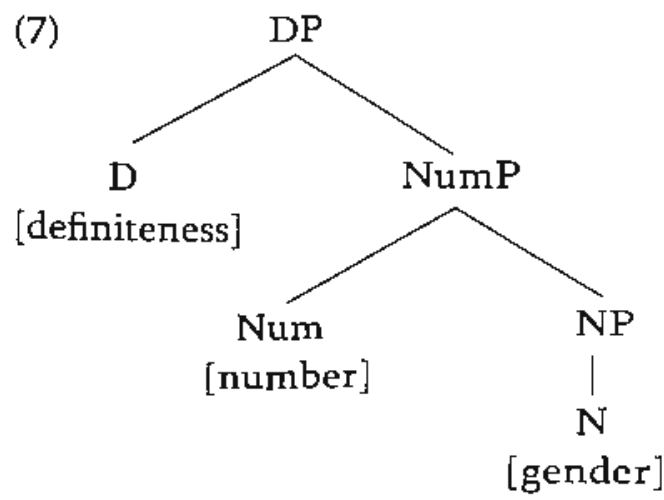

Segundo a análise de Abney (1987), a distribuiçãodos traços nominais por meio das várias cabeças representadas em (7) não se estende a pronomes porque pronomes nāo têm projeção NP. Mas, segundo Ritter, já que pronomes em hebraico desencadeiam concordância de gênero, deve ser deduzido que eles são especificados para esse rraço, mesmo que sejam apenas categorias funcionais. A hipótese de que existem duas categorias funcionais nominais distintas, D e Num, leva à expectativa de duas classes de pronomes, e a evidência do hebraico indica que isto é de fato o caso. Mais especificamente, isto motiva uma distinção estrutural entre os pronomes de $1^{\text {ta }}$ e $2^{2}$ pessoas, por um lado, e os pronomes de 3 pessoa, por outro lado. 
Tendo em vista as especificidades do hebraico, referentes às duas classes de pronomes, a autora afirma que os fatos apresentados sobre o hebraico fornecem suporte para um tratamento não unificado dos pronomes nessa língua. Mais especificamente, a autora sugere que pronomes de $1^{\text {a }}$ e 2 pessoas sâo DPs que contêm apenas a cabeça funcional D, e como esses pronomes desencadeiam concordância verbal de pessoa, número e gênero, a cabeça $D$ é especificada para esse conjunto de traços-phi, como mostrado em (8), (21) em Ritter (1995): ${ }^{10}$

(8) Representação dos pronomes de $1^{\mathrm{a}}$ e $2^{\mathrm{a}}$ pessoas em hebraico

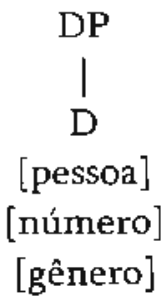

Mas os pronomes de $3^{n}$ pessoa, por apresentarem uma estrutura mais complexa, não são Ds; esses pronomes contêm um De NumP, mas não um NP, consequentemente gênero é especificado em Num, tendo assim apenas um nódulo para número e gênero. A estrutura dos pronomes de 3a pessoa em hebraico está representada em (9), (23) em Ritter (1995):

(9)

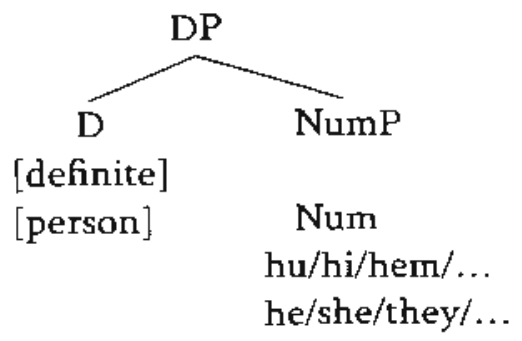

No PB, nós temos também uma distinção entre os

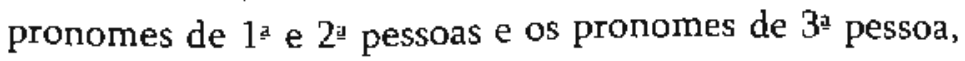

10 Considerar, ainda, que em hebraico todos esses traços-phi estāo presentes também na forma verbal. inclusive gênero, cf. noca 8. 
"A inclusão da forma pronominal năo consta nos exemplos de Kayne; nós a incluinos, por serem também formas
admitidas no francês. se bem que não seja pelas mesmas razões apontadas com relação ao hebraico. Os exemplos de (10) permitem verificar o que ocorre no PB:

\section{(10) a. eu estou interessado/a você está interessado/a \\ b. ele está interessado ela está interessada}

Salvo engano, o que verificamos com os pronomes de $3 \geq$ pessoa parece ser confirmado também no francês, pois além de os pronomes pessoais de $3^{n}$ pessoa comportarem os traços de pessoa, número e gênero, são tambérn os pronomes de $3^{a}$ pessoa, que se comportam como DPs, que estabelecem a concordância com o participio, em francês (KAYNE 1977). Alguns casos ilustram os padrões de concordância de dois tipos principais: a) o particípio concorda com o sujeito se ele é acompanhado do verbo être (ser), como em (11); b) o outro tipo é aquele em que o particípio concorda com o seu objeto direto, quando este precede o particípio, como em (12) (KAYNE 1977: 360-368):

(11) a. cette robe sera offerte à Marie par Paul b. ce bouquin scra offert à Marie par Paul

(12) a. Paul l'a mise à la porte

b. "Paul a mise Marie à la porte

Identifica-se igualmente a concordância do adjetivo com a cópula: Marie/ Elle est petite - Paul/11 est petit ${ }^{11}$.

A assimetria verificada entre as formas pronominais de $1^{\text {an }} \mathrm{e} 2^{\text {s }}$ pessoas vs. as formas de $3^{\text {n }}$ pessoa, como podemos verificar acima no $\mathrm{PB}$, mostra que, diferentemente das formas pronominais de $3^{\mathrm{n}}$ pessoa, as formas de $1^{1 !}$ e $2^{a}$ pessous não apresentam traço de gênero, e por isso, de uma única forma são derivados dois padrôes de concordância com a forma predicativa, ou seja, na t" 
e $2^{2}$ pessoas é o predicativo que comporta visivelmente os traços de gênero. $\mathrm{E}$, nesse sentido, podemos perguntar qual a motivação para as duas derivaçōes possiveis. Ou, ainda, qual o alvo do gênero, tendo em vista que ele está sempre associado a uma categoria na estrutura frásica além do DP, em várias línguas.

Cardinaletti (1994), a partir da hipótese de que há duas categorias de pronomes: os pronomes fortes e os pronomes fracos, se propôe a analisar a hipótese de que diferentes tipos de pronomes têm estrutura interna diferente. Para mostraradiferençaentreclíticosepronomes fracos, a partir de dados do sueco, a autora apresenta a hipótese de que pronomes fracos, como os pronomes fortes, são formas morfologicamente complexas: eles têrn um morfema (denominado pela autora de "morpheme of support") que é ausente nos pronomes clíticos. A distinção entre pronomes fortes e fracos, proposta por Cardinaletti, para o italiano, apresenta alguns problemas para o PB. Apesar de se tratar de uma língua românica, o italiano apresenta distinções em seu sistema pronominal quando comparado ao sistema pronominal do português. Galves (2001: 153-4) utiliza a distinçào entre pronomes fortes em oposição a deficientes, que incluem os clíricos e os pronomes fracos, de Cardinaletti \& Starke (1999), [1994], e afirma que os fatos do PB a obrigam a rediscutir as bases da tipologia proposta por Cardinaletti \& Starke, em especial a distinção, nos pronomes deficientes, entre pronomes fracos e clíticos. Em sua análise, Galves afirma que o PB representa um caso raro, no domínio das línguas românicas, de um paradigma pronominal cujos objetos diretos de primeira e segunda pessoa são clíticos, enquanto o de terceira pessoa é um pronome fraco. ${ }^{12}$

Pouquíssimas análises de alguns dos fenômenos apresentados na introdução sobre o PB têm sido realizadas no quadro da gramácica gerativa. Faremos a seguir uma breve discussão sobre fenômenos investigados no $\mathrm{PB}$, com os resultados obtidos.

Para o estudo da concordância conn a forma promominal a gente, Costa, Moura e Pereira (2001)
12 Para mais detalhes sobre a análise, ver Galves (2001). 
13 Atualmente, operação Agree (Chomsky 1999). desenvolveram uma hipótese com base na Teoria da Verificação de 'Traços (CHOMSKY 1986, 1995): ${ }^{13}$

De acordo com essa hipótese:

a) os traços gramaticais (gênero, número e pessoa) são verificados em Inf(ection), o que condiciona a concordância verbal, num domínio local;

b) asformasanafóricasconcordamcom Inflection). sendo movidas para I (núcleo fexional). Como em domínios locais, o sujeito concorda com I. é esperado que os traços gramaticais do sujeito. da Hexão e da forma anafórica concordem;

c) em domínios não locais, como a forma pronominal não é movida para I, não se espera encontrar o mesmo tipo de concordância.

Segundo essa hipótese, o tratamento teórico dado ao fenômeno da concordância permite dar conta de frases do tipo:

(13) a. Eu adorei a festa

b. A menina adorou a festa

Nos exemplos de (13), temos casos de concordância gramatical plena, tendo em vista que os traços gramaticais são verificados em Infl condicionando a concordância verbal no domínio local.

No entanto, mesmo a nível local, é possivel encontrar estratégias diferentes em construçòes em que a gente concorda com uma forma adjetival ou participial. No $\mathrm{PB}$, pode ser selecionada uma forma no masculino singular ou no feminino singular:

(14) a. A gente estava interessado b. A gente estava interessada

A primeira opção é usada se o referente de a gente só contiver elementos masculinos, e a segunda opção, se o referente só contiver elementos femininos. 
De acordo com a hipótese segundo a qual a forma anafórica loçal concorda com os traços gramaticais do sujeito devido ao papel desempenhado por I, a única solução prevista é a solução (14b), em que a forma participial/adjetival concorda com os traços gramaticais do sujeito. Também numa perspectiva de verificação de traços, esta é a hipótese que seria gramatical. Os traçosphi do sujeito desencadeariam concordância com a forma adjetival ou participial, sendo posteriormente o sujeito elevado, entrando numa relação de Spec, head agreement corn o núcleo flexional, conforme ilustrado em (15):

(15) $\left[_{\mid P}\right.$ A gente ${ }_{i(\Phi)}\left[I_{[\Phi]}\left[{ }_{V F}\right.\right.$ estava $l_{S C} t_{i}$ interessada $\left.{ }_{[\Phi]}\right]$

Considerando que os processos de concordância, dentro da small clause e no domínio de I, são acionados pela mesma expressão, é esperado que o sujeito, I e o predicativo do sujeito concordem, da mesma forma que se espera que, para efeitos de ligaçāo, o sujeito, I e a forma anafórica concordem. No entanto, a conflito detectado nos exemplos de (14) mostra que uma hipótese baseada em concordância ou verificação de traços a nivel local não é facilmente sustentável, uma vez que dois tipos de concordância são encontrados a nível local, pois uma mesma forma pronominal desencadeia dois tipos de concordância com o sintagma predicativo dentro da small clause.

A proposta de Magalhães (2004) apresenta uma série de argumentos a favor da valoração de traços de concordância dentro do DP em temos da operação Agree (Chomsky 1999), e mostra que Agree dá conta da valoração de traços tanto no nível da sentença quanto no nivel do DP, contra a sugestão de Chomsky (1999) de que a concordância no DP envolveria algum outro mecanismo de checagem.

Chomsky (1999) propōe a operação Agree como uma operação que ocorre envolvendo os elementos $\alpha$ e $\beta$, em que $\alpha$ tem traços flexionais interpretáveis e $\beta$ tem traços flexionais nâo interpretáveis; os traços não 
inrerpretáveis de $\beta$ apagam-se mediante Agree. Apesar de ser motivada pela interface, a interpretabilidade de um traço é uma propriedade inerente que está acessivel ao longo da derivação. Os traços nāo interpretáveis devem ser apagados, por essa operação, para que haja convergência da derivação. $O$ apagamento desses traços faz-se na sintaxe, aplicando-se Agree em relaçōes de concordância sob condiçōes apropriadas, e internamente a uma fase.

Magalhães conclui sua análise afirmando que primeiro ocorre a valoraçāo dos traços- $\Phi$ dos concordantes do DP e o traço de Caso do DP é valorado quando ele entra em relação de concordância com uma sonda. A valoração de traços dentro do DP acontece, então, da mesma forma que acontece a valoração de traços em construçōes participiais (Chomsky, 1999), diferindo no que diz respeito ao uso de etapas que ela assume como sendo uma consequência de sua análise.

Por outro lado, a análise de Magalhães dá conta, ainda, de estrunuras como "As menina(s) bonita(s) / Nós vai". Para a autora, nesses exemplos, os traços de número só se manifestam no argumento. $\mathrm{E}$, dessa forma, pode-se pensar que a presença de traços de número no argumento está relacionada ao fato de os traços serem interpretados nos argumentos. No momento em que há uma perda da realização da flexäo de número nos itens do sintagma, a realizaçāo fonológica dos traços se dá, exatamente, naquele item em que o traço é interpretável.

Magalhäes ratifica a hipótese de Abney (1987), de que existe uma relação selecional semântica no $\mathrm{DP}$ entre $\mathrm{D}$ e $\mathrm{N}$ semelhante à relaçào existente no IP entre o sujeito e o verbo. No DP, D é o núcleo que seleciona o NP como complemento, do mesmo modo que o VP funciona como complemento para Infl. Há, assim, uma relação argumento/predicado entre $\mathrm{D}$ e $\mathrm{N}$ no sintagma nominal, e sujeito e verbo no sintagma verbal. Na sentença, os traços de número são interpretáveis no sujeito (argumento) e não interpretáveis no verbo (predicado). $O$ mesmo 
acontece no DP: traços de número são interpretáveis no D (argumento de $\mathrm{N}$ ) e nāo interpretáveis em $\mathrm{N}$ (predicado).

$\mathrm{O}$ determinante tem traços de rúmero interpretáveis e de gênero nāo interpretáveis; o nome tem traços de número não interpretáveis e de gênero interpretáveis; já para os adjetivos esses traços são nāo interpretáveis. A autora assume com Abney (1987) e Cinque (1994) uma estrutura básica para a relação sondaalvo em DPs contendo adjetivos.

Algumas questōes com relação à proposta de Magalhäes têm a ver com a noção de fases, que são domínios onde as operaçōes de concordância acontecem. Uma estrutura é composta por várias fases; as operações repetem-se em cada fase; depois de uma fase estar completa, ela é enviada para Spell-Out e tem-se um ciclo completo. Chomsky (1999) propōe CP e vP como fronteiras de fase. Os fenômenos do $\mathrm{PB}$, ilustrados em (6 a-g), levantam problema para a concordância do sintagma predicativo, na small clause, levando em conta que o verbo cópula seleciona uma small clause, em que os traços'phi do sujeito seriam predicados ao predicativo. Esse problema é acrescido, ainda, dos casos de predicação secundária, em que a simetria com os dados de cópula é perfeita, em exemplos do tipo "a gente chegou cansado".

Pclas razões já apontadas ao longo da discussão, acreditamos que o caminho para chegarmos à análise pretendida tem a ver com a estrutura interna do DPpronominal vs. concordanncia, e a nossa expectativa é de que essa investigação possa contribuir para outros estudos relacionados à questâo da concordância no $\mathrm{PB}^{1{ }^{14}}$ it Esse texto, publicado en 2004, na Revista LEITURA, foí selecionado para ser reeditado no número especial sobre os vinte anos da PósGráduação em Letras e Linguistica da UFAL. pelos organizadores do referido númcro. Informamos aos leitores que uma nova análise do fenómeno foi apresentada no 1 Congresso Internacional de Linguistica Histótica, no período de 26 a 28/7/2009, em SalvadorBA. 


\section{Referências}

ABNEY, Steven. The English Noun Phrase in its Sentencial Aspect. Ph.D. diss.; MIT, 1987.

ANDERSON, Stephen R. Some Points of Agreement. Dept. of Linguistics, Yale University. JHU IGERT Workshop, 22 January, 2004.

CARDINALETTI, Anna. On the internal structure of pronominal DPs, in The Linguistic Revievv 11, Berlin, 1994: 195-219.

CARDINALETTI, Anna. Subject and Clause Structure, in L. Haegeman. The New Comparative Syntax. London: Longman. 1997: 33-63.

CARDINALETTI, Anna. Italian Emphatic Pronouns are Postverbal Subjects, in Working Papers di Venezia, vol. 9, 1999: 1-20.

CARDINALETTI, Anna. Toward a Carthography of Subject Positions, in Luigi Rizzi (ed.). The Structure of CP and IP. The Carthography of Syntactic Structures. Vol. 2, Oxford University Press, 2004: 115-165.

CARDINALETTI, Anna \& S'TARKE, Michal. The Typology of Structural Deficiency. A case Study of the Three Classes of Pronouns. In H. van Riemsdijk. Clitics in the Languages of Europe, EALT/EUROTYP 20-5, Berlin/New York: Mouton De Gruyter, 1999: 145-233.

CARSTENS, Vicki. Concord in Minimalist Theory. Linguistic Inquiry, vol. 31 (2), 2000: 319-335.

CHAVES DE MELO, Gladstone. Iniciação à Filologia Portuguesa, Rio de Janeiro: Livraria Acadêmica, 2đ edição, 1957.

CHOMSKY, Noam. Knowledge of Language. Its nature, origin and use. New York: Praeger, 1986. 
CHOMSKY, Noam. The Minimalist Program. Cambridge: The MIT Press, 1995.

CHOMSKY, Noam. Derivation by Phases. Ms., 1999.

CORBETT, Greville G. Gender. New York: Cambridge University Press, 1999 [1991].

CORBETT, Grevilie G. Agreement: Terms and Boundaries. In W. E. Griffin (ed.) The Role of Agreement in Narural Language: TLS 5 Proceedings. Texas Linguistic Forum, 53, 2003a: 109-122.

CORBETT, Greville G. The canonical Approach in typology. To appear in: Zygmunt Frajzyngier, David Rood \& Adam Hodges (eds.) Linguistic Diversiry and Language Theories. Amsterdam: Benjamins, 2003b.

COSTA, Joāo; MOURA, Denilda \& PEREIRA, Sandra. Concordância com a gente: um problema para a teoria de verificação de traços. Actas do XVI Encontro Nacional da Associaçãa Portuguesa de Lingüistica. Associação de Lingüística Portuguesa, Lisboa 2001: 639-655.

DANON, Gabi. The Syntax of Determiners in Hebrew. Thesis, Tel-Aviv University, May 1996.

DÉCH LINE, Rose-Marie and WILTSCHKO, Martina. Decomposing Pronouns. Linguistic Inquiry, vol. 33 (3), 2002: 409-442.

GALVES, Charlotte. Ensaios sobre as gramáticas do português. Campinas, SP: Editora da UNICAMP. 2001.

IARLEY, Heidi \& RITTER, Elizabeth. Person and number in pronouns: a feature-geometric analysis. Language 78,2002 : 482-526.

KAYNE, Richard. Syntaxe du français. Le cycle transformationnel, Paris: Éditions du Seuil, 1977 (versāo francesa de Каупе (1975)). 
MAGAlHães, Telma M. V. A Valoração de Traços de

Concordància dentro do DP. Revista DELTA, vol.20 (1), 2004: 149-170.

MENUZZI, Sérgio. First Person Plural Anaphora in Brazilian Portuguese: chains and constrains interaction in binding. In Joăo Costa (ed) Pormguese Syntax. New Comparative Seudies. Oxford University Press, 2000: 191-240.

MOURA, Denilda e FARIAS, Jair (orgs) Reflexões sobre a sintaxe do português. Maceió: Edufal, 2005.

RITTER, Elizabeth. Two functional categories in noun phrases: Evidence from Modern Hebrew, in Susan Rothstein (ed.) Syntax and semantics 26. San Diego, California: A.cademic Press, 1991: 37-62.

RITTER, Elizabeth. Where's Gender? Linguistic Inquiry, vol. 24. n. 4, 1993: 795-803.

RITTER, Elizabeth. On the syntactic category of pronouns and agreement. Natural Language and Linguistic Theory 13. 1995: 405-443.

RULLMANN, Hotze. First and Second Person Pronoun as Bound Variables. Linguistic Inquiry, vol. 35 (1), 2004: 159-168.

SAID ALI, Manuel. Gramática Histórica da Língua Portuguesa. Rio de Janeiro: Livraria Acadêmica, 7: edição, 1971.

SOUSA DA SILVEIRA. Liçōes de Português. Rio de Janeiro: Livros de Portugal, 8: edição, 1972.

TARALLO, Fernando. Tempos Lingüísticos. Itinerário histórico da língua portuguesa. Sāo Paulo: Ática, 1990.

WECHSLER, Stephen. Number as Person. Proceedings of Fifth Syntax and Semantics 